\title{
Platón en la relación intelectual de Eric Voegelin y Leo Strauss
}

\section{Plato in the intellectual relation between Eric Voegelin and Leo Strauss}

\author{
Bernat TORRES MORALES ${ }^{1}$ \\ Universidad de Barcelona \\ bernattorres@ub.edu \\ Josep MonSERRAT Molas 2 \\ Universidad de Barcelona \\ jmonserrat@ub.edu
}

Recibido: 08-03-2010

Aceptado: 09-12-2010

\section{Resumen}

Este trabajo estudia la relación entre Eric Voegelin y Leo Strauss con la finalidad de mostrar los temas centrales que permiten elucidar las posiciones filosóficas de ambos autores. El estudio de su correspondencia manifiesta la centralidad de la figura de Platón como punto desde donde entender el acuerdo y el desacuerdo de ambos autores respecto cuestiones fundamentales (como son la lectura de los textos del pasado, la perspectiva histórica con la que nos enfrentamos a ellos y la forma con la que el estudio del pasado puede orientar la situación de la ciencia moderna) y sobre el eje de la cuestión de la relación entre revelación y filosofía. El trabajo termina determinando el núcleo común que comparten ambos pensadores y a partir del cual es posible entender sus diferencias (la homogeneidad o la heterogeneidad de la realidad y de lo humano) y, además, sitúa ambas perspectivas en relación con una lectura «fundacional» (Voegelin) o «negativa» (Strauss) del pensamiento platónico.

\footnotetext{
1 Bernat Torres es investigador predoctoral de dicho grupo de investigación y becario del del Departamento de Filosofía Teorética y Práctica de la Universidad de Barcelona. Este artículo forma parte de los resultados del Proyecto de Investigación financiado por la Dirección General de Investigación del Ministerio de Ciencia e Innovación HUM2007-62763/FISO y del Grup de Recerca EIDOS. Hermenèutica i Platonisme(Universitat de Barcelona, 2009SGR447).

2 Josep Monserrat es doctor en Filosofía por la Universidad de Barcelona y profesor agregado del Departamento de Filosofía Teorética y Práctica de la Universidad de Barcelona y director del grupo de investigación «EIDOS. Hermenèutica, platonisme i modernitat».
} 
Palabras clave: Filosofía y Revelación, Filosofia Política, Historia de la Filosofia, Platón, Voegelin, Strauss.

\begin{abstract}
This essay examines the relationship between Eric Voegelin and Leo Strauss in order to show the central themes necessary to elucidate their philosophical positions. The essay reveals the centrality of the figure of Plato as a point of departure to understand the agreement and the disagreement concerning fundamental questions (such as the way of reading ancient texts, the importance of the historical perspective or the importance of the study of the past in order to orient the modern science) which revolves around the issue of the relation between revelation and philosophy. The work concludes with an identification of the common core of both thinkers that allows us to understand their differences (homogeneity or heterogeneity of reality and the human) and, moreover, identifies both perspectives with a «foundational» (Voegelin) or «negative» (Strauss) interpretation of Plato's thought.
\end{abstract}

Keywords: History of Philosophy, Philosophy and Revelation, Plato, Polilical Philosophy, Strauss, Voegelin.

El presente artículo es una contribución a los estudios existentes acerca de la relación intelectual entre Eric Voegelin y Leo Strauss ${ }^{2}$ y su propósito es profundizar en esta cuestión a partir sobretodo de la correspondencia que mantuvieron ambos pensadores y que ha sido traducida recientemente al español. ${ }^{3}$ Además, el presente estudio añade algunos elementos extraídos de la correspondencia entre Voegelin y su amigo Alfred Schütz, con quien Voegelin tuvo una relación más direc-

\footnotetext{
2 Rhodes (1987), Wiser (1993), Gadamer (1993), Pangle (1993), [los artículos de Wiser, Gadamer y Pangle, así como el de Sandoz, están incluidos en Emberly y Cooper (1993)], McAllister (1995), Opitz (2010).

3 E. Voegelin \& L. Strauss, Fe y filosofía. Correspondencia 1934-1964, edición, traducción y notas de A. Lastra y B. Torres, Madrid: Trotta (2009). Recientemente se ha publicado por primera vez la correspondencia en alemán (Opitz 2010), lengua en la cual fueron redactadas originalmente la mayoría de las cartas; en ella se añaden cuatro cartas inéditas, un extenso comentario a la correspondencia de Peter Opitz - el cual es también el editor de la obra - y, finalmente, se adjuntan unas notas también inéditas de Strauss sobre la obra de Voegelin La Nueva Ciencia de la Política (Patard 2010). Para la traducción inglesa véanse las ediciones de Emberly y Cooper (1993, 2004). A lo largo del articulo las referencias a la correspondencia se realizarán indicando la fecha original de su redacción [dd/mm/aa]. Aprovechamos la oportunidad para agradecer especialmente a Antonio Lastra, Zdravko Planinc, Richard Geldard y Stanley Rosen sus útiles comentarios relativos a diferentes cuestiones particulares que han permitido orientar nuestro trabajo.
} 
ta y abierta que la que tuvo con Strauss. ${ }^{4}$ El objetivo de nuestro trabajo es examinar la importancia que la interpretación de Platón juega en la relación entre ambos pensadores, tanto para determinar sus similitudes como sus diferencias. Por esta razón, las diferentes lecturas del pensamiento platónico que manifiestan ambos filósofos nos van a permitir situarlos en la tradición interpretativa del pensamiento de Platón, dividida desde sus orígenes entre una perspectiva dogmática y una de escéptica, y revestida de enigmas sobre las intenciones políticas del pensador ateniense. ${ }^{5}$

Uno de los principales elementos que caracteriza tanto la obra de Eric Voegelin (1901-1985) como la de Leo Strauss (1899-1973) es su pretensión de hacer frente a la situación de desorden político a través de una recuperación de la filosofía clásica, y más concretamente, a través de una recuperación de la filosofía política platónica. La correspondencia entre estos dos pensadores es un documento valioso para pensar dos formas diferentes de llevar a cabo la mencionada tarea en un sentido peculiar de lo que sea historia de la filosofía. Voegelin y Strauss viven los acontecimientos del siglo Xx desde la comprensión de sus raíces en el ámbito intelectual, filosófico o, especialmente en el caso de Voegelin, espiritual. Podríamos decir que su tarea común es la de elucidar y examinar aquello que sea relevante en el estudio del ser humano y de la vida política. Ambos consideran como un peligro la visión moderna según la cual no es posible hablar de la diferencia entre el buen y el mal gobierno, o de la justicia en un sentido objetivo, o acerca de la relación, (y esto es de nuevo más voegeliniano que straussiano), entre la ciudad y la divinidad. Podríamos decir que ambos pensadores comparten la idea central de que si las ciencias sociales no son capaces de ir más allá de la distinción entre hechos y valores, éstas no van a ser capaces de enfrentarse a una realidad que está tan llena de hechos como de valores y que no puede ser comprendida mediante un único método científico. Tanto Voegelin como Strauss comprenden la importancia de iniciar la investigación científica a partir de las mismas experiencias humanas, esto es, a partir de las opiniones como reflejo de cualquier situación humana o política. Si la ciencia no es capaz de aceptar la importancia tanto de los hechos como de los valores -y de recorrer la distancia que vincula las opiniones y el conocimiento-, ésta va a ser víctima del ocultamiento de la compleja esencia de su propio objeto de estudio. Queremos sugerir que, frente a la compleja situación política, ambos filósofos intentaron recuperar la forma de confrontación con la situación vivida que caracteriza a la ciencia política platónica y aristotélica. Pero si es el caso que comparten un diagnóstico común de la situación, resulta que nos ofrecen terapias diferentes; sus juicios son a menudo similares, mientras que las raíces de los mismos difieren profundamente.

\footnotetext{
4 Wagner y Weiss (2004).

5 Para la importancia de Platón en el pensamiento de ambos autores véase sobretodo Rosen (1958), Anastaplo (1988), Planinc (1996, 2001) y Rhodes (1992, 2001).
} 


\section{El contexto de la correspondencia y las primeras cartas: la centralidad de la ciencia política platónica}

La correspondencia entre Voegelin y Strauss empieza en 1934, pero sólo se establece de forma continuada desde comienzos de los años cuarenta y hasta 1952. Ambos pensadores se establecieron en Estados Unidos a finales de los años treinta y ambos recibieron su reconocimiento público a raíz de la publicación de sus conferencias Walgreen: Strauss en 1949 con el texto que se convertiría en Derecho e Historia Natural, publicado en 1953; y Voegelin en 1951 con el texto que se convertiría en la Nueva Ciencia de la Política, publicado en 1952. Ambos consolidaron su interés por Platón también durante los años treinta y a principios de los años cuarenta, aunque por diferentes razones: en el caso de Voegelin derivadamente de sus descubrimientos sobre la teoría de la conciencia y concretamente acerca de la importancia del mito, ${ }^{6}$ y en el caso de Strauss derivadamente de su estudio del problema teológico-político. ${ }^{7}$ La centralidad del mito como una simbolización de las experiencias existenciales en las distintas civilizaciones es un elemento clave para comprender tanto el pensamiento de Voegelin como su interpretación de Platón. Precisamente en 1943 Voegelin ve la necesidad de reorientar su investigación hacia una teoría del hombre, la sociedad y la historia sobre la base de una teoría de la conciencia que sería fuertemente influenciada por su interpretación de Platón. ${ }^{8}$ En el caso de Strauss, el problema teológico-político solo resulta comprensible a la luz de la querella entre antiguos y modernos y del conflicto entre la religión bíblica y los conceptos filosóficos. ${ }^{9}$ Debe añadirse que la correspondencia entre ambos pensa-

\footnotetext{
${ }^{6}$ La primera publicación sobre Platón de Voegelin es un artículo de 1947 (Voegelin 1947, 307-324) donde encontramos un análisis del pensamiento de Platón guiado por una interpretación del Timeo y Critias. Encontramos un amplio tratamiento de Platón en el segundo y especialmente en el tercer volumen de Order and History (Voegelin 2000a, b), donde el autor realiza diversos análisis textuales de los diálogos, junto con un estudio del contexto simbólico y el pensamiento de Platón. Es importante agregar que la mayor parte del material utilizado en estos dos volúmenes se extrae sin grandes cambios de su History of political Ideas. Referencias importantes al pensador griego se encuentran también en varios de los artículos: «The Gospel and Culture» (1971), «Reason, the classical experience» (1974) or «Equivalences of Experience and Symbolization» (1981) (Voegelin 1990a) y también en las últimas páginas del quinto volumen de Order and History (Voegelin 2000d), publicado póstumamente e inconcluso. Hay un acuerdo general entre los intérpretes en afirmar que Voegelin hace una lectura bíblica de Platón: Platón se encuentra en la línea del pensamiento profético, pero su pensamiento está demasiado vinculado a la polis griega y la idea del cosmos - esta es la lectura que orienta la interpretación que hace Voegelin del Timeo, la cual es central para entender su interpretación general del Platón. Sin embargo, como afirma Z. Planinc «aunque la lectura de Voegelin estaba profundamente influenciada por la tradición cristiana de interpretación, la propia filosofía de Voegelin era más próxima a la de su Platón que a la de su comprensión de la teología cristiana» (Planinc 2001).

7 Strauss (1953, 74-5), Tanguay (2003), Pangle (2006); Meier (2006), Brague (1998).

8 Voegelin (1990a, 3).

${ }^{9}$ Lastra (2000), Altini (2000)
} 
dores ya había finalizado en el momento de publicación de sus obras de madurez: los tres primeros volúmenes de Order and History, la obra magna de Voegelin, se publicarían entre 1956 y 1957; Strauss publicaría Thoughts on Machiavelli en 1958. No sabemos con certeza la razón por la cual finalizó la correspondencia entre ambos, aunque sobre ello se ha escrito lo suficiente y, como veremos a continuación, no son difíciles de ver los elementos fundamentales que los separaban. ${ }^{10}$ Sea como fuere, ambos pensadores han dejado una herencia clara en el ámbito de la filosofía política y además, aunque sin esperarlo ni desearlo, encontraron también un sitio en el complejo marco de la política americana. ${ }^{11}$

Veamos pues, como ya desde su inicio la correspondencia entre Voegelin y Strauss pone de manifiesto tanto un interés común como unas claras divergencias con respecto a la centralidad de la filosofía política y, más concretamente, de la filosofía platónica. En 1942, Strauss desde Nueva York y Voegelin desde Alabama, toman como tema principal de la conversación la situación de la ciencia social. Strauss escribe a Voegelin en relación con la crítica de éste último a la obra de $\mathrm{H}$. Cairns ${ }^{12}$ y le dice que su tesis, a pesar de ser totalmente correcta, no pone suficiente énfasis en la visión de la ciencia política de Platón y de Aristóteles como precedente de la situación actual: «la posición que usted ataca es sólo el último reducto [Überbleibsel] de la ciencia [Wissenschaft] establecida por Platón y Aristóteles: el postulado de una ética y una política exactas en Platón [...] la imposibilidad de fundamentar la ciencia en la fe religiosa» (24/11/1942).

Este fragmento es útil para introducir algunos elementos importantes de la controversia entre Voegelin y Strauss. En primer lugar, debe mencionarse el acuerdo fundamental sobre el hecho de que las posiciones de Platón y Aristóteles en relación con la ciencia son «el inevitable punto de partida [unvermeidliche Ausgangspunkt]» (9/12/1942). Sin embargo, según Voegelin, la filosofía política clásica se basa en la creación de un nuevo mito, esto es, una nueva explicación completamente diferente a las anteriores y con un marcado significado religioso; mientras que para Strauss no es aceptable hablar de la creación de un nuevo mito en Platón, ya que «su esfuerzo se dirigía hacia una nueva fundación de la ciencia y especialmente de la ciencia

10 Ellis Sandoz, uno de los principales editores de las obras completas de Voegelin, sostiene que es posible que, después de la publicación de la Nueva ciencia de la política en 1952, «desde la perspectiva de los dos hombres, la persuasión había llegado a su límite, y tenían poco más que decirse a causa de su desacuerdo fundamental» (Emberly y Cooper 1993, 297-300). S. Rosen, discípulo de Strauss con el cual tuvimos ocasión de intercambiar personalmente unas palabras a través del correo electrónico sobre esta cuestión particular, afirma que, «As I recall, Strauss felt he had somethings in common with Voegelin: they both represented the Continental tradition of scholarship. But Strauss found Voegelin too Christian in his reading of the Greeks.» (mensaje enviado por parte de Stanley Rosen a Bernat Torres el día 18 de abril de 2008).

11 Véase para eso último el excelente trabajo de McAllister (1995).

12 Cairns (1942), Voegelin (1942). Cairns contribuiría más adelante a la obra de P. Friedländer sobre Platón, con el capítulo «Platón como jurista» (Friedländer 1958, 286-313). 
del alma y del Estado» (24/11/1942). Strauss se distancia ya desde el principio de la perspectiva de su interlocutor según la cual filosofía y religión comparten el mismo espacio, pues defiende que filosofía (Atenas) y revelación (Jerusalen) representan dos opciones excluyentes. Pero, ¿qué quiere decir Voegelin cuando afirma que la ciencia platónica se funda en el mito? Según Voegelin, significa principalmente que esta ciencia está basada sobre ciertas experiencias fundamentales [Grunderlebnisse] vinculadas a la persona y la muerte de Sócrates: la «catarsis a través de la conciencia de la muerte y del entusiasmo de eros», los cuales «allanan el camino para la correcta ordenación del alma (Dike) [für die rechte Ordnung der Seele]». Para Voegelin, «los logros teóricos en política y ética parecen secundarios en comparación con esas experiencias fundamentales. Sólo cuando el orden fundamental [Grundordnung] del alma queda definido, resulta posible ordenar el campo de las relaciones sociales por él determinado» (9/12/1942). ${ }^{13}$

Strauss no puede aceptar la secundariedad de los logros teóricos debido a su comprensión de la ciencia, en particular, en lo que respecta a la centralidad de la distinción entre la teoría y la praxis que Voegelin no comparte. Para este último la teoría es siempre posterior a las experiencias míticas o religiosas: podríamos decir que toda teoría se funda según Voegelin en una praxis existencial, en una experiencia fundamental de carácter religioso, como la que marcó la vida y la obra de Platón. ${ }^{14}$ Este elemento es hasta tal punto crucial para Voegelin que será uno de los pilares sobre los que construirá La Nueva Ciencia de la Política, donde el orden político se muestra dependiente del reconocimiento y mantenimiento de una verdad transcendente, de una apertura del alma hacia la divinidad. ${ }^{15}$ Es más, esté elemento no solamente determinará la teoría política de Voegelin, sino su concepción filosófica global, pues tal y como le comunica a su amigo Alfred Schütz «la esencia de la filosofía se encuentra [...] en la interpretación de las experiencias de la trascendencia [Auslegung von Transzendenzerlebnissen]».16

13 Subrayado nuestro. La relación «platónica» entre el orden de la sociedad y el orden del alma (República 435de) es uno de los principales elementos que fundamentan el proyecto filosófico-político de Voegelin en La Nueva Ciencia de la Política (Voegelin 2006, 85-90; 1987, 63-68).

14 Este punto de vista puede dar lugar a confusiones importantes, como afirma Rosen: «dado que todos los símbolos tienen un referente mítico-religioso, la dimensión filosófica del mito en Platón queda oscurecido en el análisis de Voegelin. El mito es para Voegelin tanto una experiencia pre-filosófica como la filosofía misma» (Rosen, 1958, 265). Véase también Pangle 1993. Según Rosen, «los méritos del enfoque de Voegelin quedan comprometidos por su tendencia a establecer una fuerte antítesis entre las experiencias existenciales y el racionalismo» (Rosen 1958, 263). Según Anastaplo, el uso de términos como «existencial» en Voegelin «revela una susceptibilidad hacia las modas modernas» (Anastaplo 1988, 88).

15 Véase sobretodo el capítulo II (2006, 69-96).

16 Wagner y Weiss $(2004,456)$, carta de $1 / 1 / 53$. 
Es necesaria una aclaración en este punto para entender la «valentía» con la que Voegelin lee e interpreta los autores del pasado en contraposición a la «prudencia» con que lo hace Strauss. Para entender la posición del primero debemos remitirnos brevemente a su comprensión de la historia, la cual está estrechamente vinculada con su teoría de la conciencia, es decir, con su comprensión de la razón y la naturaleza humanas. Digamos para empezar que la lectura voegeliniana del pasado es fundamentalmente bíblica y, en menor medida, platónica. Nos explicaremos. Para Voegelin, el orden en la historia debe entenderse a partir del orden en el alma individual: el alma individual, la razón humana, se encuentra siempre situada en lo que él llama metaxy, esto es, en un punto medio entre el hombre y Dios, entre la inmanencia y la trascendencia, entre la ignorancia y la sabiduría o la «things-reality» y la «it-reality». ${ }^{17}$ Debe mencionarse que el término metaxy representa un término técnico necesario para comprender el conjunto de la obra de Voegelin y, concretamente, para entender la conexión mencionada entre la teoría de la conciencia, la teoría política y filosofía de la historia. Este término, que solamente queda fijado como termino técnico de manera clara en la obra tardía de Voegelin, tiene sus raíces en su lectura de ciertos diálogos de Platón y, por tanto, demuestra la centralidad que Platón tiene para este pensador. ${ }^{18}$ La situación adecuada del hombre en esta polaridad -i.e. el mantenerse siempre en medio de los extremos- es la que permite el orden del alma y, análogamente, el orden en la historia (y esto significa también el orden en las comunidades políticas, es decir, en la ciudad): de manera que las diversas reflexiones de los pensadores griegos y cristianos deben orientar nuestra acción práctica, individual y política, en tanto que en ellas se manifiesta, en un grado mayor o menor de iluminación que es describible históricamente, un orden trascendente. ${ }^{19}$ Esta posibilidad de orden transcendente y sus manifestaciones históricas son el objeto de la obra magna de Voegelin, Order and History. Así, la idea platónica según la cual existe un vínculo fundamental entre el alma humana y la ciudad es también una tesis central de Voegelin, el cual, sin embargo, va más allá de Platón al tratar la eficacia histórica de esta vinculación. Esto tiene su explicación en

17 Voegelin (1990a, 2000d).

18 Voegelin toma el termino metaxy de diversos lugares del corpus platonicum, entre los cuales encontramos Banquete (202a), Filebo (16d-e) o Fedón (81a); cf. Voegelin 1990a, 89-115 i 2000b.

19 Debe añadirse que, en su obra tardía, Voegelin reconoce que Platón no desarrolló mucho el tema del hombre como ser histórico en comparación con el tema del hombre como ser racional y político, pero, sin embargo, Platón siempre fue muy consciente de la dimensión histórica de la razón (Voegelin 1990a, 90-93, 1990b, 342-48). Es interesante en este aspecto el comentario de Stanley Rosen, cuando afirma que la cuestión del historicismo adquiere una centralidad excesiva en ambos pensadores y que «el intercambio es especialmente llamativo debido a la percepción compartida de que el historicismo, o la rendición de la razón a la interpretación perspectivista, solamente puede ser superado por el dominio hermenéutico de la historia». Y termina preguntando que «si Strauss está más cerca de la perspectiva científica de Nietzsche que Voegelin, ¿cual de los dos está más cerca de historicismo?» (Rosen 1993, 261, 266). 
su comprensión del cristianismo, la cual se manifiesta claramente en su comentario sobre la obra de Cairns: «la aparición de Cristo ha sumado a la idea del hombre la dimensión espiritual de la singularidad de cada ser humano, de modo que ya no podemos construir el orden social, por ejemplo, en antropologías como las de Platón y Aristóteles». ${ }^{20}$ Por lo tanto, Voegelin considera que el modelo platónico de ciencia es el fundamento de toda ciencia humana y social, pero sin embargo está limitado porque no es capaz de acceder a la verdadera situación del hombre en el todo. Las causas de esta limitación, la cual no hay que entender en un sentido negativo, quedan esclarecidas a lo largo de la obra de Voegelin. Digamos aquí simplemente que se debe principalmente a la centralidad de la polis y a la visión de un cosmos que aún no permite acceder plenamente a la trascendencia. Todo esto hace, según el pensador alemán, «radicalmente imposible» la universalidad [Generalisierung] de la ciencia platónico-aristotélica, la cual es solamente posible gracias a la imagen del hombre simbolizada por la revelación de Cristo: «la sustitución del hombre helenocéntrico por el individuo, la persona en comunicación directa con Dios» $(9 / 12 / 1942) .21$

Frente a esto, Strauss niega decisivamente que la ciencia platónica sea «en su intención griega» y no universalizable (20/12/1942), es decir, niega que pueda o deba ser entendida históricamente. Strauss, evidentemente, no contempla la continuidad histórica entre el pensamiento griego y el cristianismo en el mismo sentido que lo hace Voegelin. Para Strauss, la filosofía es fundamentalmente la lectura y el examen de los grandes textos del pasado, su complejidad intrínseca y la manera como estos pueden permitirnos pensar mejor el hombre y su relación con la ciudad. Pero en esta tarea la filosofía y la reflexión racional están totalmente desvinculadas de las experiencias religiosas: la filosofía es la búsqueda incesante de la verdad, la religión es la obediencia derivada de la ley divina. Por esta razón Strauss no puede aceptar de ninguna manera que «el cristianismo y el descubrimiento de la historia han desechado [erledigt] el concepto platónico-aristotélico de ciencia» (24/11/1942). Voegelin matiza a su interlocutor que más que de 'desechar' se trata de un cambio de los mitos fundamentales que permite pensar el hombre en su comunicación directa con la divinidad: esto es lo que hace posible la situación correcta del hombre en el todo. Strauss no puede aceptar, sin embargo, esta perspectiva: en primer lugar porque la situación del hombre en el todo representa una elección o bien a favor de la filosofía o bien a favor de la revelación, pero no es posible encon-

\footnotetext{
20 Voegelin $(1942,562-63)$.

${ }^{21}$ Hay que añadir aquí que aunque la comprensión de Platón a lo largo de la obra de Voegelin es predominantemente bíblica, su comprensión de la historia como una línea de proceso con un máximo en la revelación cristiana se transforma en su obra tardía, donde centra su análisis sigue una línea discontinua que obliga a examinar la historia «hacia atrás, hacia adelante y hacia los lados» (comparar Voegelin 2001 con Voegelin 2000c y ver también Rhodes 1992).
} 
trar un punto medio como pretende Voegelin en la forma del mito o de la revelación. Para Strauss es inevitable elegir entre Jerusalén o la revelación por una parte y Atenas o la filosofía por otra;22 para Voegelin es inevitable no pensar al hombre como situado siempre en medio (en la metaxy) de la filosofía y la revelación. ${ }^{23} \mathrm{En}$ segundo lugar, porque Strauss considera que antes de poder situar el pensamiento Platón y su verdadero significado histórico es necesario esclarecer la intención de Platón: «sólo se puede decidir mediante una interpretación radical e implacable de cada diálogo platónico en sus propios términos o, en la medida de lo posible, de cualquier diálogo platónico en sí mismo. Por esta razón, una discusión por carta es de hecho imposible» (20/12/1942).

Así pues, encontramos ya en éste primer intercambio las que sin duda van a ser las dos cuestiones fundamentales que centraran el intercambio entre ambos pensadores, a saber, el problema de la revelación y su relación con la filosofía y, en segundo lugar, el problema de la interpretación del diálogo platónico y su filosofía política. Las diferencias fundamentales con respecto a estas cuestiones no impedirán, sin embargo, que la relación intelectual entre ambos pensadores se prolongue fructíferamente durante más de diez años. Su interés por la filosofía clásica y concretamente por el pensamiento platónico mantendrá viva la relación.

\section{Los textos clásicos y la historia}

Uno de los principales frutos de la relación entre Voegelin y Strauss es el relativo a la publicación en 1948 de Sobre la Tiranía, 24 texto sobre el que Voegelin escribe una reseña que despierta el interés de Strauss y a la cual este último acabará respondiendo. 25 En su correspondencia, Voegelin elogia claramente el trabajo de Strauss (14/1/1949), pero su comentario a Schütz tiene otro tono: «el análisis del Hierón es excelente y se expone con gran cuidado y erudición. El resto (todas las referencias a los antiguos, a los modernos, las comparaciones con Maquiavelo, etc.) no es tan atractivo». ${ }^{26}$ En definitiva, Voegelin dice claramente a su amigo Schütz que Strauss hace muy bien la tarea de interpretar textos, pero que a nivel histórico

22 Cf. Strauss 1967, 1989, 258-262.

23 Sin embrago, no es fácil clasificar a Voegelin como cristiano. En un intercambio de mensajes con Richard Geldard, este afirmo que «[a]t the Centennial celebrations of EV's birth in 2001 (San Francisco), informal discussions in the general session made it clear that EV was not a Christian believer in any traditional sense. He used Christian imagery in a symbolic sense to draw comparisons to the philosophical search for the divine ground.» (Correo enviado por R. Geldard a B. Torres el 01/08/07).

24 Strauss (1948).

25 Lastra y Torres $(2009,44-55)$.

26 Wagner y Weiss $(2004,344)$. 
su trabajo deja mucho que desear. Este hecho tiene, por supuesto, mucho que ver con la intención filosófica del trabajo de Strauss, mucho más centrado en la comprensión de los textos que en la interpretación de su dimensión histórica. En su reseña, Voegelin critica la profunda relación que establece Strauss entre el tirano Hierón y el príncipe de Maquiavelo, afirmando que «'la tiranía moderna' seguirá siendo ininteligible a menos que tengamos en cuenta el hecho de que es un fenómeno occidental, no griego». Strauss es tajante respecto este punto en su respuesta a la reseña de Voegelin: «Una ciencia social que no pueda hablar de la tiranía con la misma confianza con la que la medicina habla, por ejemplo, del cáncer, no puede entender los fenómenos sociales como lo que son. Por tanto no será científica». Para Strauss, la cuestión del buen y el mal gobierno es una cuestión de carácter ahistórico, es decir, una cuestión puramente teórica, y es la cuestión básica de la ciencia social y la principal contribución de la filosofía política clásica. Para Voegelin, la diferencia -claramente histórica- entre el constitucionalismo y postconstitucionalismo es más fundamental que aquella. Al final de su respuesta a la reseña de Voegelin, Strauss escribe que «necesitamos una segunda educación para acostumbrar nuestros ojos a la noble reserva y a la tranquila grandeza de los clási$\cos \gg .{ }^{27}$

De nuevo, pues, los dos pensadores nos presentan dos formas distintas de aproximarse a los textos y al pensamiento del pasado. En el transfondo de la discusión se encuentra nuevamente la problemática de pensar la filosofía desde una perspectiva histórica o, dicho de otro modo, el problema de hasta que punto la filosofía política es también una filosofía de la historia. 28 Como hemos visto, la historia es para Voegelin el proceso en el cual los hombres encuentran, con momentos de mayor o menor apertura, su lugar en el todo, es decir, en el metaxy. ${ }^{29}$ Por esta razón la comprensión de la historia está estrechamente vinculada o supeditada a su filosofía política; como afirmará más adelante en su Nueva Ciencia de la Política: «que el máximo de diferenciación se haya logrado por medio de la filosofía griega y del cristianismo significa, concretamente, que la teoría debe moverse en el horizonte histórico de las experiencias clásicas y cristianas. Apartarse del máximo de diferenciación es un retroceso teórico. Derivará - concluye Voegelin - en los distintos tipos de desvío que Platón caracterizó como doxa».30 Para Strauss, sin embargo, no tiene sentido hablar de una nueva ciencia política, pues la ciencia política es esencial-

\footnotetext{
27 Lastra y Torres $(2009,54)$.

28 Patard 2010, 145-147.

29 «No hay otra historia que la que se constituye en la metaxy de la conciencia diferenciadora» (Voegelin 2000c, 234).

${ }^{30}$ Voegelin $(2006,101 ; 1987,79)$. En este sentido se debe entender la afirmación de que «si el hombre existe en la metaxy, en la tensión entre dios y el hombre, cualquier tipo de construcción del hombre como entidad meramente inmanente del mundo destruye el sentido de su existencia, porque priva al hombre de su humanidad específica» (Voegelin 1990a, 104).
} 
mente clásica y su objeto de estudio son siempre las cuestiones fundamentales. Así pues, frente a la lectura de la filosofía platónica como encaminamiento hacía la apertura a la transcendencia en el transcurrir histórico que propone Voegelin, Strauss afirma tajantemente que la filosofía clásica es decididamente ahistórica. La filosofía clásica en general y los diálogos platónicos en particular tienen como objeto las cuestiones fundamentales, es decir, «1) la cuestión del arje o los arjai, 2) la cuestión de la vida justa o la ariste politeia. La "historia" en sentido estricto - añade Strauss- pertenece a la dimensión práctica, a la dimensión subordinada a lo teorético. Historizar significa olvidarse de la eternidad. Este olvido ha de ser entendido en términos de rechazo al concepto clásico de filosofía» (10/12/1950).

A través de la problemática relativa a la historicidad o no de la filosofía política, nos adentramos en otra cuestión de gran importancia a la que alude Strauss en está discusión. Se trata de la diferencia, según él descuidada por parte de Voegelin, ente la teoría y la praxis. Strauss sostiene que la palabra «existencial», utilizada por Voegelin a menudo, oculta la distinción fundamental entre teoría y praxis, y añade que «las raíces de la oscuridad moderna desde el siglo XVII se encuentran en la ocultación de las diferencias entre teoría y praxis» (14/03/1950). Además, esta confusión imposibilita según Strauss la comprensión de Platón. La experiencia existencial de Voegelin se enfrenta aquí con la heterogeneidad entre teoría y praxis defendida por Strauss. Creemos que esta diferencia fundamental entre ambos autores, la cual no fue tematizada a lo largo de su correspondencia, nos indica la posibilidad de hacer inteligible aquello que separa a ambos pensadores. Esta dicotomía, más o menos clara, nos permite situar en el ámbito ontológico o metafísico la discusión entre Voegelin y Strauss, la cual evita hablar de estas cuestiones y se centra más bien en la problemática histórica que hemos venido exponiendo hasta ahora. ${ }^{31}$

\section{Los principales desacuerdos entre Voegelin y Strauss: Platón y la revelación}

Las cartas escritas entre febrero y abril de 1951 son los principales documentos para aclarar la controversia entre Voegelin y Strauss, sobre todo en cuanto a sus diferencias con respecto a la interpretación de Platón. Es el momento del reconocimiento explícito de «los puntos cardinales [Kardinalpunkte] en los que nuestros puntos de vista probablemente difieren»: se trata, como ya avanzábamos, del pro-

\footnotetext{
31 En este sentido nuestra lectura podría estar de acuerdo con la apreciación de Rosen en su comentario a la correspondencia, donde afirma que la cuestión del historicismo adquiere una centralidad excesiva en ambos pensadores y que «el intercambio es especialmente llamativo debido a la percepción compartida de que el historicismo, o la rendición de la razón a la interpretación perspectivista, solamente puede ser superado por el dominio hermenéutico de la historia». Y termina preguntando que «si Strauss está más cerca de la perspectiva científica de Nietzsche que Voegelin, ¿cual de los dos está más cerca de historicismo?». Cf. Rosen (1993, 261, 266).
} 
blema de la revelación y del diálogo platónico. Antes de examinar estos dos problemas es necesario mencionar algunas cuestiones importantes. En febrero de 1951, Voegelin, después de leer Philosophie und Gesetz [Filosofía y Ley], ${ }^{2}$ dice: «tengo la impresión de que se ha retirado usted de la comprensión de la fundación profética (religiosa) del filosofar (con la que yo estaría profundamente de acuerdo) a favor de una teoría de la episteme, y de que rechaza ver el problema de la episteme en conexión con la vivencia de la que surge. No sé por qué hace esto» (21/02/1951). Voegelin le pregunta cómo es posible desde esta posición enfrentarse al tratamiento de problemas tales como la interpretación de los mitos platónicos. Strauss responde afirmando que «hay, como puede imaginar, un punto en el que nuestros caminos se separan» (25/02/1951). Esta separación de caminos tiene que ver con lo que Strauss afirma a continuación cuando dice que él sigue creyendo «que las theioi nomoi [leyes divinas] son la base común de la Biblia y la filosofía, hablando en un sentido humano» y añade que es el problema de la multiplicidad de las leyes divinas el que lleva a las soluciones diametralmente opuestas de la Biblia por una parte y de la filosofía por otra. La diferencia que establece Strauss entre lo profético y lo filosófico se basa en el hecho de que "los clásicos de la ciencia son los griegos y no la Biblia. Los clásicos demostraron que la verdadera vida humana es la dedicada a la ciencia, al conocimiento y a su búsqueda. El hen anagkeion [lo único necesario] de la Biblia es algo completamente distinto. No tiene ningún sentido ocultar esta contraposición postulando la existencia de un tertium. Toda síntesis es, de hecho, optar por Jerusalén o por Atenas》 (25/02/1951).

Nos enfrentamos aquí a la diferencia fundamental entre ambos pensadores, la relación entre filosofía y revelación, vinculada a la cuestión de la homogeneidado heterogeneidad de la realidad $33 \mathrm{y}$, por lo tanto, con la manera con la que el hombre se enfrenta a lo que es. La visión profética o mítica del origen de la filosofía en Voegelin se enfrenta a la diferenciación radical entre filosofía y religión de Strauss, la cual debemos situar, como acabamos de ver, en relación con la cuestión de la multitud de leyes. Esta fundamental diferencia esconde, sin embargo, una importante coincidencia relativa a la tensión fundamental en el que ambos filósofos sitúan al ser humano. Esto es así en tanto que Voegelin y Strauss 1/ consideran que el ser humano está situado en una irreductible tensión entre dos polos; 2/ consideran que esta tensión permite aclarar el devenir de los seres humanos en la historia, y, además, 3/ consideran que la pérdida de esta tensión representa un gran peligro.

\footnotetext{
32 Strauss $(1935,1987)$.

33 Esta diferencia, situa de nuevo en el centro de la polémica la signficación de Platón. Como afirma Rosen, Voegelin malinterpreta la concepción platónica de la naturaleza porque «en su lectura, la naturaleza humana es homogénea (porque todos los hombres se encuentran infinitamente separados de Dios), mientras que para Platón, es claramente heterogénea. Son los modelos humanos estables, y no un misterio espiritual, los que hacen de la filosofía política una empresa racional» (Rosen 1958, 273).
} 
Así pues, el ser humano se nos presenta en ambos casos enfrentado a la necesidad de situarse a sí mismo en el todo y, por lo tanto, entre los polos que constituyen su naturaleza. Habiendo, pues, encontrado esta coincidencia fundamental, podemos ahora disponernos a descender, a partir de ella, a las diferencias.

1/ Habiendo mostrado que la estructura que caracteriza el pensamiento de ambos autores es tensional, la primera diferencia fundamental debe situarse en el origen de esta tensión. Como hemos dicho, en Strauss el origen está representado por la multiplicidad de leyes o, en otras palabras, por la heterogeneidad de la realidad, de la cual nacen las dos respuestas opuestas de la Biblia y la filosofía. En el caso de Voegelin, el origen de la tensión no es la heterogeneidad, sino más bien la unidad o la homogeneidad de la realidad, la cual se manifiesta en su comprensión de las experiencias existenciales o transcendentes como esencia de la filosofía, «los símbolos son muchos, mientras que lo que es es uno». ${ }^{34}$ La certeza de esta unidad o homogeneidad del ser tiene como consecuencia su búsqueda del orden a lo largo de la historia, la cual, a pesar de la multiplicidad de experiencias y símbolos, puede reducirse a una estructura homogénea, la metaxy; «los movimientos del encuentro divinidad-hombre se entienden en tanto que forman una unidad inteligible de sentido, la cual es noética tanto en su fondo como en su estructura». 35 Por lo tanto, afirmamos que una de las diferencias fundamentales entre ambos filósofos radica en su comprensión de la realidad y de la naturaleza humana en relación con su homogeneidad o heterogeneidad, y que esta diferencia se deriva de la estructura tensional de sus pensamientos. Esta diferencia nos lleva a indicar los polos de las tensiones que ya hemos mencionado más arriba (inmanencia / trascendencia, o humano / divino en Voegelin; Jerusalén / Atenas, es decir, religión / filosofía, profecía / sabiduría en Strauss ${ }^{36}$ ). Como hemos visto, en el caso de Voegelin el lugar apropiado para el hombre es el término medio entre los extremos, la metaxy; mientras que en Strauss resulta imprescindible escoger entre uno de los polos, es decir, que resulta esencial el situarnos fuera de la metaxy, aunque esto signifique un peligro. Así pues, lo homogéneo nos sitúa en medio, mientras que lo heterogéneo nos impulsa hacia los extremos.

2/ Voegelin tiene la pretensión de explicar la historia de la humanidad a través de los grados de diferenciación -o equivalencias- en los cuales la verdad se manifiesta a sí misma en diferentes momentos históricos y a través de diferentes filósofos. ${ }^{37}$ Strauss, consecuentemente con la heterogeneidad, habla de la diferencia o de

\footnotetext{
34 Voegelin $(2001,46)$.

35 Voegelin (1990a, 97). Además, hay que añadir que está certeza tiene su origen en la experiencia de la fe en el sentido en que la entiende Voegelin, la cual es definida como «la sustancia de las cosas esperadas, y la prueba de la existencia de las cosas invisibles» (Hebreos 11,1) (Voegelin 2004, 177 y ss.). 36 Strauss (1967); comparar con Strauss (1989, 254-256).

37 Voegelin (2000a, b, c, d, 2001).
} 
la irreductibilidad -más que de la diferenciación o de la equivalencia- en el conjunto de la realidad:38 para la filosofía no hay nada superior a la razón, mientras que la religión depende de una revelación divina a la que la razón debe someterse, y «en toda síntesis, por impresionante que sea, uno de los dos elementos opuestos queda sacrificado». Es el llamado problema teológico-político, la tensión que según Strauss se encuentra en el corazón de Occidente y que es todavía una de las principales causas de la crisis de nuestro tiempo. Desde el punto de vista de Strauss, Voegelin ha «sacrificado» la posibilidad de dirigir su vida a través de sus facultades naturales y "sin ayudas externas». 39 Desde el punto de vista de Voegelin, la posición de Strauss ignora los peligros de la inmanentización del eskhathon.

3/ Es importante notar que Voegelin y Strauss comparten el diagnóstico de la crisis moderna y están de acuerdo en que el relativismo y el dogmatismo son los grandes peligros de nuestro tiempo, pero sus terapias difieren en consecuencia con los motivos de su juicio, es decir, con el núcleo de su comprensión del todo sobre el que tratamos. Según Voegelin, la salud de la ciudad, de la filosofia y de la ciencia moderna dependen de la cooperación entre filosofía y revelación; la revelación necesita de la filosofía para evitar el peligro de caer en el dogmatismo, mientras que la filosofía necesita del conocimiento revelado para no romper con su origen divino, es decir, para mantener la correcta dirección de la búsqueda filosófica y evitar así el escepticismo y el relativismo. Según Strauss, la salud de la ciudad, de la filosofía y de la ciencia moderna dependen de mantener viva la tensión entre Atenas y Jerusalén, a fin de evitar las posiciones extremas que ellas mismos representan: el escepticismo o el relativismo sofista como una forma de degradación de la sabiduría humana por un lado, y el dogmatismo religioso como una degradación del conocimiento profético por el otro. ${ }^{40} \mathrm{~A}$ pesar, pues, de la coincidencia en el problema, las terapias entre ambos pensadores difieren. En un caso somos inducidos a la unión prudente entre nuestra parte humana y nuestra parte divina; en el otro se nos advierte sobre la necesidad de separar la búsqueda racional de la obediencia revelada. Veamos a continuación como este hecho se manifiesta en la comprensión que ambos autores tienen del problema de la revelación y del diálogo platónico. Para ello, volvamos ahora a las cartas relativas a los dos «puntos cardinales» mencionados.

Estamos en abril de 1951: Voegelin está preparando sus Walgreen Lectures, el texto que resultará la Nueva ciencia de la política, y expresa su agradecimiento a

\footnotetext{
38 Strauss (1975a, 1988b).

39 Strauss $(1953,74-75)$.

40 cf. Sales \& Monserrat 1991.

41 Strauss (1950a). Voegelin posiblemente tuvo acceso a otra interpretación straussiana de Hobbes (Strauss 1936) donde Strauss sostiene que las ideas de Hobbes no surgieron de la tradición o de la ciencia, sino de su propia experiencia y de su profundo conocimiento de la naturaleza humana. Strauss,
} 
Strauss por haber enviado sus obras sobre Hobbes ${ }^{41}$ y Weber ${ }^{42}$. La larga carta de Voegelin tiene la forma de un ensayo, y su objetivo es exponer en detalle su punto de vista sobre los dos grandes desacuerdos entre él y Strauss, es decir, la revelación y el diálogo platónico. En cuanto a la cuestión de la revelación, Voegelin comienza con la definición de Agustín de conocimiento revelado como «el conocimiento previamente dado a la consciencia [Vorgegebenheiten der Erkenntnis] (sapientia, estrechamente relacionada con el nous aristotélico y diferente de la episteme)» (22/04/1951). El conocimiento previamente dado es también la experiencia del hombre como esse, nosse, velle, y a éste tipo de conocimiento pertenece también el del ser de Dios más allá del tiempo. Como se lo mencionó a Strauss, esta experiencia ha de entenderse como el origen de la episteme, cosa que Strauss no parece poder aceptar. Como hemos visto, Voegelin considera que el conocimiento revelado aparece en relación con determinados acontecimientos históricos de la conciencia humana o del alma en los que «el hombre se desdiviniza sí mismo y se da cuenta de la humanidad de su vida espiritual» (22/04/1951). Sólo gracias a esta concentración espiritual será posible experimentarse a uno mismo como siendo llamado por un Dios trascendente. Es en este sentido que el cristianismo ha absorbido y enriquecido la comprensión del alma alcanzada por los griegos.

Strauss responde a la cuestión de la revelación aceptando que «debe asumirse que algo que viene de Dios le ocurre al hombre [etwas von Gott her geschieht]», pero este acontecimiento «no es necesario entenderlo como llamada o interpelación; ésa es una interpretación posible, cuya aceptación se basa, por tanto, en la fe y no en el conocimiento. Voy más allá: hay una diferencia fundamental entre la llamada de Dios mismo y la formulación humana de esa llamada; lo que encontramos históricamente es lo segundo» (04/06/1951). Ya hemos visto que es efectivamente desde la fe que Voegelin afirma su posición, la cual pretende justamente saber interpretar las formulaciones humanas de la palabra divina, cosa que es para Strauss radicalmente problemática debido a nuestra falta de criterios para discernir entre formulaciones legítimas e ilegítimas. Por lo tanto, contra la posición de Voegelin, la revelación no puede ser, según Strauss, un tipo de conocimiento. Por otra parte, Strauss añade que el problema es cristiano o judío y, precisamente por eso, no es «universal y humano» (04/06/1951). ${ }^{43}$ Esto significa que presupone «una fe especi-

siguiendo el desarrollo de la doctrina moral de Hobbes desde sus primeros escritos hasta el Leviatán, pone de manifiesto diversas contradicciones en la obra de Hobbes y descubre sorprendentes conexiones entre Hobbes y el pensamiento de Platón, Tucídides, Aristóteles, Descartes, Spinoza y Hegel. Este punto de vista se puede encontrar también en la obra de Voegelin, sobre todo, la relación que este establece entre Platón y Hobbes. Véase la Nueva ciencia de la política, especialmente el capítulo V y comienzo del capítulo VI (Voegelin 2006; 1987); véase también Voegelin 1999.

42 Strauss $(1951,1953)$. Schütz, en 1951 afirma que la interpretación de Weber que hace Strauss parece ser derivada de la Voegelin (Wagner y Weiss, 2004, 384).

43 cf. Strauss (1993). 
fica [spezifischen Glauben], lo que la filosofía, como filosofía, no hace ni podría hacer. Aquí y sólo aquí se encuentra la diferencia [Divergenz] entre nosotros, también en lo meramente histórico». Nos enfrentamos una vez más al núcleo del desacuerdo entre Voegelin y Strauss. ${ }^{44}$ Desde nuestro punto de vista, esta cuestión central nos remite a la pregunta sobre que sea aquello que descubre, aquello que en última instancia persigue la búsqueda filosófica: la filosofía nos descubre una realidad a través de una multiplicidad de símbolos y diferenciaciones, o nos descubre la misma multiplicidad que constituye la realidad a través de una búsqueda racional -no revelada. Eso es obviamente importante para entender las posiciones generales de ambos autores, pero también para entender su interpretación de Platón, sobre la que dedicaremos el resto del artículo.

Estamos ya en disposición de esclarecer el segundo de los desacuerdos entre Voegelin y Strauss, el relativo a la significación de la obra platónica, uno de los temas que como hemos señalado a lo largo del artículo, aparece de una u otra forma a lo largo de toda la correspondencia. El tema de la centralidad del mito en Platón era ya el tema del primer intercambio sobre la crítica de Voegelin a Cairns. En febrero de 1951, Strauss reprende esta cuestión y le dice a Voegelin: «parece usted muy seguro de que los mitos platónicos sólo son comprensibles si postulamos una experiencia "religiosa" subyacente. Yo no estoy tan seguro al respecto. Confieso mi ignorancia» (25/02/1951). Fijémonos que la posición straussiana no es de negación de la centralidad del hecho religioso, sino de escepticismo frente a su verdadera significación filosófica. Strauss es consecuente con su posición, lee a Platón desde Atenas. Añade que le parece imposible resolver el problema del mito platónico antes de haber resuelto el problema del diálogo platónico, es decir, del cosmos de los diálogos (25/02/1951). Voegelin, por decirlo así, ya ha resuelto el problema del diálogo platónico gracias a verlo a través de su visión unitaria donde el mito se erige como origen de la reflexión científica: Voegelin, por decirlo usando la terminología straussiana, lee a Platón desde Jerusalén. Para Strauss, la obra de Platón «consta de muchos diálogos, ya que imita la multiplicidad, la variedad y la heterogeneidad del ser» ${ }^{45} \mathrm{La}$ visión heterogénea y homogénea de ambos pensadores se manifiesta, pues, también en su interpretación de la obra de Platón. Además, Strauss afirma que Platón «estaba menos interesado en llevar a los mejores lectores a creer que a pensar, y para eso no hay mejor medio que la forma enigmática de su obra en general $y$ de los mitos en particular» (25/02/1951). Esta diferencia entre 'creer' y 'pensar',

\footnotetext{
44 Es importante mencionar aquí que Strauss admite que «la filosofía ha de conceder que la revelación es posible. Sin embargo, conceder que la revelación es posible es conceder que la filosofía quizás no sea la única cosa necesaria [...] o que la filosofía tiene una debilidad fatal» (Strauss 1953, 75); «la filosofia o la ciencia, la llamemos como la llamemos, es incapaz de dar cuenta de su propia necesidad» (Strauss 1989, 269-270).
}

45 Strauss $(1989,154)$. 
sin embargo, no es clara en Voegelin, pues en el núcleo de su pensamiento se encuentra el poder de la fe: para él, negar la fe es negar la fuente misma desde donde hacer inteligible nuestro pensar mismo, pues pensar adecuadamente es pensar movidos por la trascendencia, una trascendencia que no vemos pero que esperamos y deseamos. ${ }^{46}$ Strauss es en este punto una vez más concluyente al afirmar que «cualquiera que sea el significado de noein [conocer], desde luego no es pistis [creencia] en ningún sentido. En este punto Heidegger [...] simplemente acierta» (10/12/1950).

La exposición de lo que Voegelin llama, posiblemente utilizando algún tipo de ironía platónica, «el segundo pequeño problema, el diálogo platónico» (22/04/1951), empieza por la aceptación de la tesis de Strauss según la cual «nada decente está disponible sobre la cuestión y que el estado del conocimiento es más bien insatisfactorio», pero añade que «la dificultad de comprenderlo se debe más a l'embarras de richesse de los motivos que a la imposibilidad de encontrarlos»" (22/04/1951). Voegelin expone su interpretación de los principios del diálogo platónico en diez puntos, que son, si los leemos cuidadosamente, diez posibles definiciones del diálogo platónico que conforman una visión global unitaria clara: 47

/1/ El diálogo es la «continuación [Fortsetzung] de la tragedia de Esquilo bajo nuevas circunstancias históricas y políticas», concretamente en una situación de corrupción generalizada que ha llevado al asesinato de Sócrates; el diálogo es así una forma de persuasión (peitho) que persigue la imposición del orden correcto en el alma y en la ciudad. 48 /2/ El diálogo es la forma requerida de expresión del problema del alma, -vinculado con el principio también esquileo y platónico de la polis como un hombre escrito en grandes caracteres (República VIII-IX)- cuando este problema, el orden del alma [Seelenordnung], es una «conversación social que funciona». /3/ Cuando el público de Atenas no escucha, el contenido del diálogo «ya no es un culto político como la tragedia esquilea, sino que se convierte en una obra

46 Recordemos que la fe es para Voegelin «la sustancia de las cosas esperadas, y la prueba de la existencia de las cosas invisibles» (Hebreos 11,1).

47 Es importante decir que estos principios interpretativos de 1951 están implícitamente presentes en el texto de la Nueva Ciencia de la Política de 1952, y explícitamente ampliados y acompañados de interpretaciones textuales de algunos diálogos platónicos en el segundo y el tercer volúmenes de Order and History.

48 «peitho» significa, según Voegelin, la comunicación persuasiva de la verdad, sobre todo la verdad del orden existencial. Este tipo de persuasión requiere la creación de una comunidad espiritual, la cual requiere a su turno la correspondiente diferenciación del alma. Además, el «peitho» a menudo se opone a la fuerza o la coacción en la vida política. Esta diferencia es fundamental para entender la interpretación que Voegelin hace de la evolución entre la República (donde sólo encontramos persuasión) y las Leyes (donde la persuasión debe combinarse con la fuerza). Voegelin identifica la coacción con el adoctrinamiento y éstos con la progresiva desaparición de los elementos dramáticos en los diálogos platónicos: «solamente cuando las tensiones en conflicto han disminuido y el nuevo orden se ha establecido, puede su expresión asumir la forma de una dogma o una proposición metafísica. Tendencias en este sentido se observan en la obra tardía de Platón; y la forma no dramática irrumpe a través de la obra esotérica de Aristóteles» (Voegelin, 2000b, 65 y ss.). 
literaria exotérica destinada a todo aquel que quiera escuchar» (digresión del Teeteto). /4/ El diálogo es el arma para la restauración del orden público [der öffentlichen Ordnung] en contra de la retórica (Gorgias y Protágoras). /5/ Si el peitho dialógica no mueve al adversario, el «diálogo continúa y el líder ultramundano del diálogo [die jenseitige Führer des Dialogs] es un juez que tiene a su disposición sanciones curativas y punitivas. No podemos escapar de la conversación». Esto explica los mitos de Gorgias y la República. /6/ «El diálogo es en sí un tribunal mítico [Gerichtsverfahren]», donde los dioses, representados por Sócrates, juzgan a la ciudad de Atenas (Apología). /7/ «Cuando la conversación se lleva a cabo con éxito», para llevar a cabo la fundación de la comunidad a través de eros, el diálogo «no es una "doctrina", sino un despertar dialógico a través de la palabra viva», donde el silencio y la dramaticidad tienen una gran importancia (Banquete, Fedro, Teages). /8/ El diálogo es una conversación erótica con el claro objetivo de conducirnos hacia la periagoge del Agathon [la conversión hacia el Bien], ${ }^{49} \mathrm{y}$, al hacerlo, esta vinculando el mito con la historia primordial a través del conocimiento socrático del orden, expresado en el mito de la Atlántida, que tiene paralelismos con la escatología occidental (República, Timeo, Critias). ${ }^{50}$ /9/ El diálogo es, en el caso de las Leyes, un mito, el cual «sigue una analogía cósmica que, en la explicación de las instituciones de la polis, se convierte en el contenido del diálogo»./10/ El diálogo no parece manifestar una verdad revelada, el mito representa una forma intermedia entre la simbolización politeísta y revelación de origen divino: «Dios no habla inmediatamente, sino sólo mediante Sócrates-Platón [...] la máxima expresión del politeísmo teomórfico parece ser la última razón de la forma del diálogo, lo divino y lo humano todavía no están completamente separados». Voegelin, al final de su exposición, le dice a Strauss que «[d]esde luego no es que una cuestión así no pueda ser esclarecida, si realmente lo intentamos. Tengo curiosidad por saber qué dirá sobre este intento».

Así pues, en conjunto, la cuestión del diálogo hay que entenderla en relación con el problema del mito platónico, el cual solamente se puede explicar a través de su estrecha relación con la cuestión de la revelación. ${ }^{51}$ Platón se describe así como

49 La periagoge, el darse la vuelta, la conversión, es un termino central del vocabulario de Voegelin; significaría en Platón la reorientación cognitiva y moral hacia la verdad y el bien como tal. También tiene el significado de la «apertura del alma» de Bergson (Voegelin 1990a, 98).

50 Voegelin está muy orgulloso de este descubrimiento, al cual llegó principalmente a través de sus estudios sobre Schelling y Vico (Voegelin de 1947; cf. carta de Voegelin a William Y. Elliot del 29 de enero de 1947).

51 En su correspondencia con Schütz, encontramos sólo una referencia a esta conversación con Strauss: Voegelin esta hablando con Schütz acerca de la comunicación de los ángeles y de la participación en la sapientia y la scientia Dei como elemento oculto en la fenomenología de Husserl y afirma que «todo tiene que ver $-\mathrm{y}$ sobre este punto he tenido un largo intercambio con Strauss respecto a la cuestión de "¿por qué Platón escribió diálogos?"- con un problema de comunicación» (Wagner y Weiss, 2004, 399). El subrayado es nuestro, comparar con la décima definición del diálogo platónico. 
un pensador que se encuentra entre el politeísmo griego y el contacto profético con Dios. Estas limitaciones platónicas estarían vinculadas al hecho que Platón centrase su reflexión en la polis griega y al hecho que su idea del cosmos no fuese suficientemente amplia. La capacidad que manifiesta Voegelin para hablar de las intenciones platónicas hay que entenderla como combinación entre su capacidad para leer los textos del pasado y su capacidad de interpretar las experiencias de la trascendencia: en este sentido, la multiplicidad de intenciones que manifiestan los diálogos, nos remiten según Voegelin a un fondo homogéneo e unitario. Esta unidad, proveniente de una lectura bíblica de Platón 52 que, como hemos visto, no solamente se manifiesta en su lectura del pensador ateniense, es justamente lo que diferencia la lectura Voegelin de la de Strauss, mucho más escéptica y, en este sentido, mucho más atenta a la heterogeneidad que manifiestan los diálogos platónicos y a la realidad que estos describen.

Strauss comienza su respuesta al texto de Voegelin afirmando: «encuentro su explicación relativa al diálogo platónico interesante y relevante en grado máximo. Sólo puedo indicar mis reservas» (04/06/1951). Las «reservas» de Strauss podrían resumirse con la siguiente frase: «El diálogo platónico no puede entenderse simplemente desde el interior de la polis sino más bien por la filosofía. Por esta razón no podemos hablar de "la conversación": todo depende de con quién hable Sócrates. El filósofo está, de hecho, esencialmente hablando [redend] y no "haciendo" [tuend]; en este sentido la conversación podría no terminar nunca. Pero la conversación que en última instancia no se dirige hacia la filosofía no es una conversación» $(04 / 06 / 1951)$.

Empecemos por la negativa de Strauss a identificar la filosofía con la polis 53 . Como hemos dicho, efectivamente, Voegelin considera que Platón es incapaz (en términos generales) de superar los límites de la polis y el cosmos, razón por la cual no puede establecer una ciencia realmente universal. Sin embargo, como hemos visto, Voegelin no entiende los diálogos de Platón simplemente desde la polis, sino desde la tensión constituida por la estructura cuaternaria formada por el hombre, la sociedad, la divinidad y el cosmos. Esta estructura, la metaxy, representa el todo en

52 Planinc sostiene que «el aspecto más radical y más platónico de la fillosofía de Voegelin es su comprensión de las equivalencias de la experiencia y la simbolización, y que el pleno significado de esta cuestión queda oscurecido por su asociación con la distinción entre «compactación» y «diferenciación», una distinción que resulta insuficiente, cuando no trivial o irrelevante, a los efectos de la mayoría de las exégesis textuales, ya que tiende a distorsionar las experiencias equivalentes en un sentido bíblico e histórico-genético. Los análisis de los diálogos platónicos son anteriores, por desgracia, a sus primeras y mejores análisis de las equivalencias» (Planinc 2007).

53 Dejaremos aquí de lado la interesante sugerencia de Strauss según la cual la lectura que hace Voegelin de Platón sólo habla de la tragedia y guarda silencio acerca de la comedia. Diremos solamente que este hecho tiene probablemente que ver con la relación entre Jesús y Sócrates, el optimismo socrático es el final de la tragedia (Strauss, 1989, 105-106) y Jesús nos acerca a la tragedia, en la que nunca se ríe. 
el que el hombre puede situarse a sí mismo para alcanzar la máxima apertura hacia la trascendencia o, dicho de otra manera, para alcanzar el orden en el interior del alma y en la ciudad. Como hemos visto, la filosofía en el sentido socrático es para Strauss la comprensión de la totalidad mediante la heterogeneidad noética o el sentido común. Recordemos que es a partir de esta heterogeneidad que es posible la distinción entre lo político y lo no político. La afirmación de Strauss muestra claramente que hay algo que trasciende la vida política, y este algo es la filosofía, hacia la cual se dirige el diálogo platónico en última instancia; y es en este sentido que el diálogo puede orientar la vida política54. Vemos pues que ambos pensadores entienden que la filosofía tiene como principal objetivo la orientación de la vida política y que la diferencia principal es el lugar donde ambos sitúan aquello que la trasciende o la orienta. La filosofía política se encuentra, según Strauss, limitada por aquello a lo que la mente humana puede acceder sin ayuda externa y la revelación divina está más allá de este límite. Así se lo expresa a su interlocutor afirmando que «Sócrates sabía que el hen anangkaion es deloun o skopein» (04/06/1951), es decir, que lo único necesario es el mostrar y la búsqueda. Contra Voegelin, en la búsqueda en la que consiste el diálogo no es posible encontrar la conversación, porque cualquier diálogo platónico imita la multiplicidad, la heterogeneidad, del ser. ${ }^{55} \mathrm{Sin}$ embargo, según Voegelin - aunque no se lo exprese de esta manera a su interlocutor-no hay zetesis (búsqueda) sin helkein, es decir, sin el poder de la atracción ejercida por la trascendencia: toda búsqueda humana es un contacto humano-divino que puede ser más o menos luminoso. ${ }^{56} \mathrm{La}$ trascendencia en Strauss -muy próxima a la de Husserl- es vista desde la perspectiva del ser humano que investiga y intenta comprender la realidad desde sus propias limitaciones, sin la ayuda de la luz divina; para Voegelin, sin esta luz divina, sin una orientación trascendente que guíe nuestra búsqueda, no tiene sentido pensar la posibilidad del orden ni en el alma humana ni en la ciudad. En última instancia, sin esta luz divina, el hombre corre el peligro de perderse en la mera inmanencia de un mundo vacío de sentido.

Lo que en Voegelin es la voz «divina» de los diálogos - una voz divina aún no completamente revelada-, es para Strauss la principal dificultad para comprender el pensamiento de Platón, es decir, la ausencia de afirmaciones no mediadas dramáticamente. ${ }^{57}$ Inversamente, lo que para Strauss es la verdadera significación del pensamiento platónico, su capacidad de captar la heterogeneidad de la realidad, la descripción multifacética del ser, representa para la interpretación de Voegelin una difi-

\footnotetext{
54 «La vida política deriva su dignidad de algo que trasciende la misma vida política» (Strauss 1989, 161-162). Aquí podemos plantear la importante cuestión de qué sea la filosofía para Strauss.

55 Strauss (1978a, 62).

56 Voegelin (1990a, 93-94).

57 «El problema del diálogo platónico es, en cierto sentido, irresoluble, pues no existen afirmaciones platónicas acerca del significado de los diálogos platónicos» (Strauss, 1989, 151).
} 
cultad que impide ver el significado unitario del pensamiento platónico y que la hermenéutica voegeliniana justifica con argumentos histórico-existenciales. Esta importante diferencia interpretativa explica la razón por la cual la atención a los elementos dramáticos del diálogo (su heterogeneidad) es más intensa en Strauss que en Voegelin (interesante en este sentido es pensar en la definición $7^{\text {a }}$ de Voegelin). Si, como afirma Strauss, la filosofía es «la forma más elevada de unión entre coraje y moderación», 58 Voegelin parece acercarse al coraje, mientras que Strauss tiende a la moderación: Voegelin ve más allá de lo que el diálogo afirma, Strauss no encuentra respuesta más allá de ellos. Eso nos explica desde otro punto de vista la forma en que ambos filósofos leen a Platón: por un lado, la lectura valiente y a veces dogmática de Voegelin interpreta a Platón desde una concepción clara de la estructura de la conciencia y su desarrollo en la historia del orden; por otro lado, la lectura moderada y escéptica de Strauss pretende, en primer lugar dejar hablar a los diálogos más allá de esquemas o premisas externas a la misma situación dramática, pero supone al mismo tiempo que tal situación sólo puede ser entendida si leemos entre líneas. 59

\section{Conclusiones: Fundación o negatividad, entre San Agustín y Lessing}

Contra Voegelin, Strauss considera que el filósofo más que a la acción (o a generar creencia) se dedica a la reflexión, es decir, en el caso de Platón, a la conversación. Nos enfrentamos de nuevo con la cuestión de la diferencia entre teoría y praxis a la que hemos aludido más arriba, la cual nos conduce a la diferencia entre la intención fundacional del diálogo platónico que presupone Voegelin frente a la intención principalmente negativa que presupone Strauss. Como hemos visto, Voegelin considera que el diálogo platónico tiene como objetivo final la constitución de una nueva comunidad erótica entendida como un conjunto de conocimientos que permitan al hombre orientarse en su relación con Dios, la sociedad y el cosmos. Frente a esto, Strauss afirmará que no es posible encontrar ningún proyecto político claro en los diálogos platónicos. ${ }^{60}$ Es también en este sentido que no es posible entender el diálogo desde la polis, porque la principal tarea de la filosofía es la preservación de la mejor forma de vida, que no es la vida política, aunque efectivamente la vida política derive su dignidad de aquella forma de vida, a saber, de la vida filosófica. ${ }^{61}$ En este sentido, la intención última del diálogo platónico sería

\footnotetext{
58 Strauss $(1988 b, 40)$.

59 Strauss $(1995,3-5)$.

60 Anastaplo comparte la posición de su maestro Strauss y añade que posiblemente el «Sr. Voegelin entiende estas cuestiones porque ve a Platón como si fuese él mismo» (Anastaplo 1988, 87).

61 Strauss (1945).
} 
la búsqueda, en la multiplicidad de la realidad, de sus leyes, fundaciones, saberes y dioses: la investigación filosófica se mueve claramente en la heterogeneidad de la realidad, refutando, desde la negatividad, las falsas sabidurías y las falsas fundaciones. Para entender la posición de Strauss relativa a la conservación de la filosofía como la mejor forma de vida, es necesario mencionar su principio hermenéutico según el cual los textos filosóficos deben leerse tanto en forma esotérica como exotérica: ${ }^{62}$ los filósofos han sido «impulsados a la conclusión de que la comunicación pública de la verdad científica o filosófica era imposible o indeseable» $\mathrm{y}$, en consecuencia, deciden enseñar la verdad esotéricamente a la minoría filosófica, mientras que reservan el uso de las «nobles mentiras» o las opiniones -las cuales «no se son en todos los aspectos consonantes con la verdad»- para la mayoría no filosófica. Voegelin, como Strauss, tiene por objeto preservar la salud del alma y de la ciudad, pero para él la «noble mentira» platónica «se transforma sutilmente en la gran verdad», esto es, en la realidad (aletheia) de la igualdad y la hermandad entre los hombres (República 414d). ${ }^{63}$ Según Strauss, esta interpretación basada en la comprensión de las experiencias «existenciales» no tiene en cuenta la experiencia fundamental de la distinción entre la teoría y la praxis, con la que sólo resultaría posible «rechazar, pero no entender, a Platón» (14/03/1950).

Esta cuestión fundamental nos permite ver como las posiciones de Voegelin y Strauss en relación con Platón pueden ser aclaradas a través de sus respectivas lecturas de Agustín y Lessing. Nos encontramos frente a la cuestión de la última intención del diálogo platónico, la cuestión relativa a su intención política y filosófica. Evidentemente, no pretendemos aquí resolver esta cuestión, sino solamente arrojar algo de luz sobre la comprensión que ambos autores tenían de la misma. Creemos que el pensamiento de Platón debe ser entendido a partir de una situación en la que un conjunto de discursos con pretensión de sabiduría se enfrentan en el ámbito público: la sabiduría homérica, el tradicionalismo aristofánico, el relativismo sofista, etc. En este contexto, la pregunta es si la intención de Platón se dirige hacia la fundación de una nueva sabiduría capaz de ser aplicada a la realidad de la polis (Voegelin), o si el filósofo ateniense pretendía hacer una investigación en este conjunto de discursos con la finalidad de desenmascarar las falsas sabidurías a través del instrumento del diálogo y la Academia (Strauss).

Strauss sitúa a Lessing como el primero que puso de manifiesto y entendió la diferencia entre la escritura esotérica y exotérica: la diferencia entre la moralidad del filósofo y la moralidad del principiante; por este motivo afirma Strauss que «los

\footnotetext{
62 Strauss (1988a; 1989, 63-71). Para entender la posición de Voegelin frente al esoterismo de Strauss vean las cartas sobre Locke (15-20/04/1953 y 29/04/1953). Voegelin duda si enviar a Strauss una fuerte crítica a las «estafas» de John Locke y finalmente parece sustituir esta carta por una menos valiente donde sólo le pregunta a Strauss si Locke sigue siendo un filósofo en absoluto.

63 Voegelin (2000b, 159-160).
} 
diálogos de Lessing [...] probablemente se acercan más al espíritu de los diálogos platónicos y a su técnica que cualquier otra obra moderna». 64 Con el fin de mostrar los peligros de la comprensión religiosa de la verdad como una posesión, Lessing escribió que «si Dios tuviera en su mano derecha toda la verdad, y en su izquierda solamente el impulso hacia la búsqueda de la verdad, aunque con la advertencia que yo debería para siempre errar en el proceso, y al ofrecerme la elección diciéndome: ¡escoge! yo escogería con toda humildad la mano izquierda, y diría: ¡dámela Padre! la pura verdad es solamente para ti».65 No es necesario explicar el inmenso contraste entre la imagen de Dios y el hombre que nos trasmite Lessing y la de Agustín de Hipona: digamos solamente que para Agustín la respuesta es Dios, es decir, la vita beata. Si revisamos la obra de Voegelin, veremos que sus usos de Agustín sólo son comparables a sus usos de Platón, lo que explica la importancia de términos como los de «luminosidad» o «metaxy».66 Se puede afirmar que Voegelin aplicó su apropiación de la experiencia clásica de la razón para transponer en términos contemporáneos el experimento anamnéstico de Agustín en las Confesiones y su teoría política de la historia en la Civitas Dei. En su análisis de la República (592b), Voegelin sostiene que «el salto existencial [leap in being] hacia la fuente trascendente del orden es real en Platón y, posteriormente, se ha reconocido con acierto que el pasaje es una prefiguración 67 de la concepción de la Civitas Dei de san Agustín».68

Nos enfrentamos, pues, a dos formas diferentes de entender la intención última de Platón y de la filosofía misma: la tendencia straussiana hacia la búsqueda incesante en una realidad esencialmente heterogénea, frente a la convicción voegeliniana de la existencia de una fundación que ya ha sido completada, que es una y homogénea, aunque siga siendo esencialmente trascendente. La elección entre una lectura lessingiana o agustiniana de Platón es, desde nuestro punto de vista, la elección entre fundación o negatividad. Esta elección se encuentra, por supuesto, vinculada con la posición dogmática o escéptica frente a la lectura de los diálogos

\footnotetext{
64 Strauss $(1989,69)$.

65 Lessing $(1979,32-33)$.

66 «Esta comprensión del carácter inter-medio de la conciencia, así como la de su luminosidad -la cual no es la luminosidad de una conciencia subjetiva, sino de la realidad de que desde ambos lados entrada en la experiencia- dio lugar a una mejor comprensión del problema de la símbolos» (Voegelin 2006, 99).

67 El término «prefiguración» se transforma a menudo en el termino «equivalencia», que expresan mejor la comprensión de Voegelin de la historia y la naturaleza humanas. Como lo expresa Rhodes, la posición de Voegelin no era la del antropólogo cultural, ni la del historicista radical o del relativista negador de la verdad. Por el contrario, su posición fue la del generoso reconocimiento de la verdad en sitios en los que no estamos acostumbrados a reconocerla, el reconocimiento de la capacidad humana para simbolizar las mismas verdades en formas diferentes pero equivalentes» (Rhodes 1992, 642-643). 68 Voegelin $(2000 \mathrm{~b}, 146)$.
} 
platónicos que mencionamos al inicio del presente artículo. La cuestión de la intención fundacional o negativa del diálogo de Platón sigue estando, con todo, abierta. Como hemos dicho ya, pese a las profundas diferencias entre ambos pensadores, la intención política de los diálogos platónicos permanece como constante y es sobre ella que ambos pensadores persiguen en sus respectivas obras orientar la ciencia política moderna. Añadamos finalmente que ambos métodos interpretativos pueden aportar luz a la complejidad intrínseca de los diálogos y del pensamiento platónico, y que a pesar de la distancia que los separa, o, precisamente, por la distancia que los separa, permiten, desde su particular posición, una aplicación que oriente el trabajo de la interpretación de los diálogos platónicos de manera fructífera. ${ }^{69}$

\section{Bibliografía}

Altini, C. 2000. Leo Strauss. Linguaggio del potere e linguaggio della filosofia. Bologna: il Mulino.

AnastaPlo, G. 1988. On how Eric Voegelin has read Plato and Aristotle. Independent Journal of Philosophy 5/6: 85-91.

Brague, R. 1998. Athens, Jerusalem, Mecca: Leo Strauss's 'Muslim' Understanding of Greek Philosophy. Poetics Today 19 (2): 235-259.

CAIRns, H. 1942. The Theory of Legal Science, Chapel Hill: North Carolina UP.

FriedLÄNDER, P. 1958. Plato: an introduction. vol. I. New York: Bollingen Foundation.

Emberly, P. and Cooper, B. 1993. Faith and Political Philosophy. The correspondence between Leo Strauss and Eric Voegelin 1934-1964. The Pennsylvania State University Press. Pennsylvania.

Emberly, P. and Cooper, B. 2004. Faith and Political Philosophy. The correspondence between Leo Strauss and Eric Voegelin 1934-1964, 2nd ed. Columbia: University of Missouri Press.

GonZalez, F. J. 1995 The Third Way, Maryland: Lanham.

Lastra, A. La naturaleza de la filosofia política. Un ensayo sobre Leo Strauss, Murcia: Res Publica, 2000.

Lastra, A., Torres, B. (edición, introducción, traducción y notas) 2009. Fe y filosofia. Correspondencia 1934-1964 (E. Voegelin, L. Strauss), Madrid: Trotta. Lessing, G. E. 1979. Anti-Goetze: Eine Duplik (1778). Ed. H. Göpfert. Werke 8. MCAllister, T. V. 1995. Revolt Against Modernity. Leo Strauss and Eric Voegelin $\&$ the Search for a Postliberal Order. Kansas: University Press of Kansas.

\footnotetext{
${ }^{69}$ Ejemplos irrefutables de ello son los trabajos de Planinc (1991) y Rhodes (2003), en los cuales se combina la perspectiva voegeliniana y straussiana de manera fructífera. Con ello inciden en la adecuación de los principios hermenéuticos desarrollados en la interpretación de Platón (Monserrat, 2002, 7-25).
} 
Meier, H. 2006. Leo Strauss and the Theologico-Political Problem, Translated by M. Brainard. Modern European Philosophy. Cambridge: Cambridge University Press.

Monserrat, J. 2002. Hermenèutica i Platonisme. Barcelona: Barcelonesa d'Edicions.

Opitz, P. (ed.) 2010. Glaube und Wissen. Der Briefwechsel zwischen Eric Voegelin und Leo Strauss von 1934 bis 1964, München: Wilhelm Fink Verlag.

OpITZ, P. 2010. Seelenverwandtschaften - Zum Briefwechsel von Eric Voegelin und Leo Strauss. In Glaube und Wissen. (op. cit.), 157-208.

Pangle, Th. L. 2006. Leo Strauss: An Introduction to His Thought and Intellectual Legacy, Baltimore: The Johns Hopkins University Press, 2006.

Patard, E. 2010. Leo Strauss' Anmerkungen zu Eric Voegelins The New Science of Politics. In Glaube und Wissen. (op. cit.), 129-147.

Planinc, Z. 1991. Plato's Political Philosophy. Prudence in the Republic and the Laws. London: Duckworth.

Planinc, Z. 1996 The Uses of Plato in Voegelin's Philosophy. Lecture, McMaster University. 12th Annual Meeting, San Francisco.

Planinc, Z. 2001 [1997]. The Significance of Plato's Timaeus and Critias in Eric Voegein's Philosophy. In Politics, Order and History. ed. G. Hughes, S. McKnight and G. L. Price. 327-375. Sheffield: Sheffield Academic Press.

Planinc, Z. 2007. Equivalences of Experience and Symbolization in Plato and Homer. Lecture, Chicago: 23rd Annual International Meeting. Eric Voegelin Society.

Rhodes, J. M. 1987. Philosophy, Revelation, and Political Theory: Leo Strauss and Eric Voegelin. The Journal of Politics 49 (4): 1036-1060.

Rhodes, J. M. 1992. On Voegelin: His Collected Works and His Significance. The Review of Politics 54 (4): 621-647.

RHodes, J. M. 2001. An old Obligation. Lecture. San Francisco, California: Annual Meeting Papers. Eric Voegelin Society

Rhodes, J. M. 2003. Eros, Wisdom, and Silence. Plato's Erotic Dialogues. Columbia and London: University of Missouri Press.

Rosen, S. 1958. Order and History. Review of Metaphysics 12: 257-284.

Rosen, S. 1993. Politics or Transcendence? Responding to historicism. In a Faith and Political Philosophy. The correspondence between Leo Strauss and Eric Voegelin 1934-1964, ed. P. Emberly and B. Cooper, 261-267. Pennsylvania: The Pennsylvania State University Press.

Sales, J. \& Monserrat, J. Introducció a la lectura de Leo Strauss. Jerusalem $i$ Atenes, Barcelona: Barcelonesa d'Edicions 1991.

Strauss, L. 1935. Philosophie und Gesetz: Beiträge zum Verständniss Maimunis und seiner Vorläufer. Berlin: Schocken [English edition: Philosophy and Law: 
Essays Toward the Understanding of Maimonides and his Predeccesors. Philadelphia: Jewish Publication Society of America, 1987].

Strauss, L. 1936. The Political Philosophy of Hobbes: Its Basis and Its Genesis, Oxford: Clarendon Press.

Strauss, L. 1945. Farabi's Plato, American Academy for Jewish Research, Louis Ginsberg Jubilee Volume: 357-393.

Strauss, L. 1948. On Tyranny: An Interpretation of Xenophon's 'Hiero'. New York: Political Science Classics [Sobre la tiranía, trad. de L. Rodríguez, Madrid: Encuentro, 2005].

Strauss, L. 1950a. On the Spirit of Hobbes' Political Philosophy. Revue Internationale de Philosophie 4 (14): 405-431.

Strauss, L. 1950b. Natural Right and the Historical Approach. Review of Politics 12 (4): 422-442.

Strauss, L. 1951. The Social Science of Max Weber. Measure 2 (2): 204-230. [Reedit. in Natural Right and History. Chicago and London: University of Chicago Press. 1953].

StRauss, L. 1953. Natural Right and History. Chicago and London: University of Chicago Press.

Strauss, L. 1967. Jerusalem and Athens. Some Preliminary Reflections. The City College Papers 6: $28 \mathrm{pp}$.

Strauss, L. 1975a. The argument and the action of Plato's Laws. Chicago y Londres: University of Chicago Press.

Strauss, L. 1975b. The Three Waves of Modernity. In Political Philosophy: Six Essays by Leo Strauss. ed. Hilail Gildin, 81-98. Indianapolis and New York: Bobbs Merrill/Pegasus.

Strauss, L. 1978 [1958]. Thoughts on Machiavelli. Chicago: University of Chicago Press.

Strauss, L. 1978a. The City and Man. Chicago and London: University of Chicago Press.

Strauss, L. 1988a. Persecution and the art of writing. Chicago: University of Chicago Press.

STRAuss, L. 1988b. What is Political philosophy? Chicago: University of Chicago Press.

Strauss, L. 1989. The Rebirth of Classical Political Rationalism, ed. Th. L. Pangle, Chicago \& London: The Chicago University Press.

Strauss, L. 1993. The mutual influence of Theology and Philosophy. In Faith and Political Philosophy. The correspondence between Leo Strauss and Eric Voegelin 1934-1964, ed. P. Emberly and B. Cooper, 217-233. Pennsylvania: The Pennsylvania State University Press. 
Strauss, L. 1995. The Liberalism of Classical Political Philosophy. In Liberal Ancient and Modern, 26-65. Chicago and London: The University of Chicago Press.

Tanguay, D. 2003. Leo Strauss: Une biographie intellectuelle. Paris: Grasset.

TARrant, H. A. 2000 Plato's First Interpreters, London, Duckworth and Ithaca: Cornel.

TORRES, B. 2008. Eric Voegelin, un filósofo de la transcendencia. La Torre del Virrey: revista de estudios culturales 5, pp.67-69.

Voegelin, E. 1939. Die Politischen Religionen. Stockholm. Bermann-Fischer Verlag. [Reeditado en Modernity without Restraint: The Political Religions; The New Science of Politics; and Science, Politics, and Gnosticism. The Collected Works of Eric Voegelin. vol 5. Columbia and London: University of Missouri Press. 1999].

Voegelin, E. 1942. The Theory of Legal Science: A Review. Louisiana Law Review 4, pp. 554-571

Voegelin, E. 1947. Plato's Egyptian Myth. The Journal of Politics 9 (3): 307-324. Voegelin, E. 1953. The Oxford Political Philosophers. The Philosophical Quaterly 3 (11): 97-114.

Voegelin, E. 1981. Equivalences of experiences and symbolization in History. Philosophical Studies 28 (2): 88-102.

Voegelin, E. 1987 [1952] New Science of Politics. Chicago: Univeristy of Chicago Press. [Reeditado en: Modernity without Restraint: The Political Religions; The New Science of Politics; and Science, Politics, and Gnosticism. The Collected Works of Eric Voegelin. vol 5. Columbia and London: University of Missouri Press. 1999].

Voegelin, E. 1990a. Anamnesis. Columbia and London: Universiti of Missoury Press. [Reeditado en: Anamnesis: On the Theory of History and Politics. Ed. David Walsh. The Collected Works of Eric Voegelin. vol. 6. Columbia and London. University of Missouri Press. 2002].

Voegelin, E. 1990b. Published Essays, 1966-1985. Ed. Ellis Sandoz. The Collected Works of Eric Voegelin, vol. 12. Columbia and London: University of Missouri Press.

Voegelin, E. 1990c. The beginning and the beyond: a meditation on truth. In What is history? and other late unpublished writings. Ed. Thomas A. Hollweck and Paul Caringella. The Collected Works of Eric Voegelin, vol. 28. Columbia and London: University of Missouri Press.

Voegelin, E. 1999. History of Political Ideas, Volume VII, The New Order and Last Orientation. Ed. Jürgen Gebhardt and Thomas A. Hollweck. The Collected Works of Eric Voegelin. vol. 25. Columbia and London: University of Missouri Press. 
Voegelin, E. 2000a Order and History, Volume II, The World of the Polis. Ed. Athanasios Moulakis. The Collected Works of Eric Voegelin. vol. 15. Columbia and London: University of Missouri Press.

Voegelin, E. 2000b. Order and History, Volume III, Plato and Aristotle. Ed. Dante Germino. The Collected Works of Eric Voegelin. vol 16. Columbia and London: University of Missouri Press.

Voegelin, E. 2000c. Order and History, Volume IV, The Ecuminic Age. Ed. Michael Franz. The Collected Works of Eric Voegelin. vol 17. Columbia and London: University of Missouri Press.

Voegelin, E. 2000d. Order and History, Volume V, In Search of Order. Ed. Ellis Sandoz. The Collected Works of Eric Voegelin. vol 18. Columbia and London: University of Missouri Press.

Voegelin, E. 2001. Order and History, Volume I, Israel and Revelation. Ed. Maurice P. Hogan. The Collected Works of Eric Voegelin. vol 14. Columbia and London: University of Missouri Press.

Voegelin, E. 2004 [1967]. Immortality: Experience and Symbol. In Faith and Political Philosophy. The correspondence between Leo Strauss and Eric Voegelin 1934-1964, ed. P. Emberly and B. Cooper, 2nd ed, 177-217. Columbia: University of Missouri Press.

Voegelin, E. 2006. Autobiographical reflections. Revised edition, with Voegelin Glossary and cumulative index. Ed. E. Sandoz, The Collected Works of Eric Voegelin vol. 34. Columbia and London: University of Missouri Press.

Voegelin, E. 2006. La Nueva Ciencia de la Política. Una introducción. trad. Joaquín Ibarburu. Buenos Aires: Katz.

Wagner, G and Weiss, G. 2004. Alfred Schütz und Eric Voegelin, "Eine Freundschaft, die ein Leben ausgehalten hat». Briefwechsel 1938-1959. Konstanz: Universitätsverlag Konstanz. 